\title{
River Water Purifier as an Alternative for Clean Water Supply in Sei Siarti Village, Panai Tengah District, Labuhanbatu Regency
}

\author{
Azhari $^{\left.1^{*}\right)}$, Tulus Ikhsan Nasution; ${ }^{1)}$, Astrid Fauzia Dewinta ${ }^{2)}$, Koko Sujatmoko $^{3)}$, M.Rifai \\ Piliang ${ }^{4)}$, Rahmadhani Banurea ${ }^{1)}$, Lukman Hakim ${ }^{1)}$ \\ ${ }^{1}$ ) Faculty of Mathematics And Natural Sciences, Universitas Sumatera Utara, Medan \\ 2) Faculty of Agriculture, Universitas Sumatera Utara, Medan \\ ${ }^{3}$ ) Faculty of Humanities, Universitas Sumatera Utara, Medan \\ ${ }^{4}$ ) Integrated Research Laboratory Technical Service Unit, Universitas Sumatera Utara, \\ Medan \\ *Email: azhari @usu.ac.id
}

\begin{abstract}
Sei Siarti Village, Panai Tengah District, Labuhanbatu Regency have problems in the form of limited clean water sources that are suitable for use. There are several potentials including peat water, drilled well water, and Barumun river water that crosses the village. The condition of peat water that does not comply with quality standards for water that is fit for consumption has a brownish color, high acidity, and the organic matter contained in peat water is high enough to cause an odor. The well water has a salty taste (high salt content) so that what has the potential is Barumun river water even though it has a cloudy color. The method used to purify cloudy river water is through the processes of coagulation (deposition), filtration (filtering), absorption (absorption), and adsorption (ion exchange). This water purifier is made using 2 tubes filled with silica sand, MGS, activated carbon, and zeolite sand so that the water produced is clear and fit for consumption and can be utilized by the surrounding community. The results obtained from this water purification are water that does not have a smell, taste, and is clear in color so that it is suitable for use by the surrounding community.
\end{abstract}

Keyword: Water Purifier, River, Panai Tengah

\begin{abstract}
Abstrak
Desa Sei Siarti, Kecamatan Panai Tengah, Kabupaten Labuhanbatu mengalami kendala berupa keterbatasan sumber air bersih yang layak pakai. Potensi tersebut antara lain air gambut, air sumur bor, dan air sungai Barumun yang melintasi desa. Kondisi air gambut yang tidak memenuhi baku mutu air yang layak konsumsi memiliki warna kecoklatan, keasaman tinggi, dan kandungan bahan organik yang terkandung dalam air gambut cukup tinggi sehingga menimbulkan bau. Air sumur memiliki rasa asin (kadar garam tinggi) sehingga yang berpotensi adalah air sungai Barumun walaupun warnanya keruh. Metode yang digunakan untuk menjernihkan air sungai keruh adalah melalui proses koagulasi (pengendapan), filtrasi (penyaringan), absorpsi (absorpsi), dan adsorpsi (pertukaran ion). Penjernih air ini dibuat dengan menggunakan 2 tabung yang berisi pasir silika, MGS, karbon aktif, dan pasir zeolit sehingga air yang dihasilkan jernih dan layak untuk dikonsumsi serta dapat dimanfaatkan oleh masyarakat sekitar. Hasil yang didapat dari penjernihan air ini adalah air yang tidak berbau, tidak berasa, dan memiliki warna yang bening sehingga cocok untuk digunakan oleh masyarakat sekitar.
\end{abstract}

Kata Kunci: Alat Penjernih Air, Sungai, Panai Tengah

\section{PENDAHULUAN}

Desa Sei Siarti merupakan salah satu desa yang berada di Kecamatan Panai Tengah Kabupaten Labuhanbatu. Jarakanya sekitar $82 \mathrm{~km}$ dari kota Rantauprapat (perjalanan kurang lebih 5 sampai 6 
jam menggunakan mobil) dikarenakan jalan yang rusak parah ketika menuju ke lokasi. Oleh karena itu Desa Sei Siarti merupakan salah satu desa terpencil yang terletak di Kecamatan Panai Tengah Kabupaten Labuhanbatu Sumatera Utara.

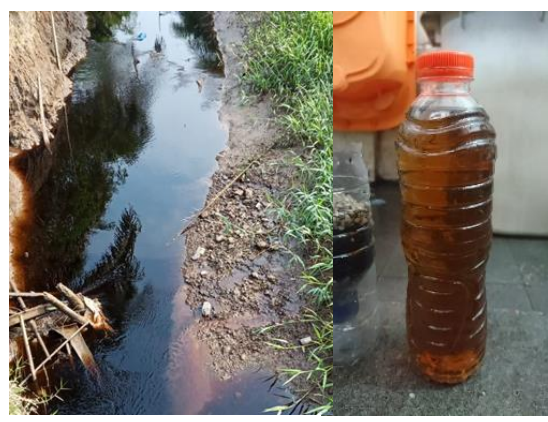

(a)

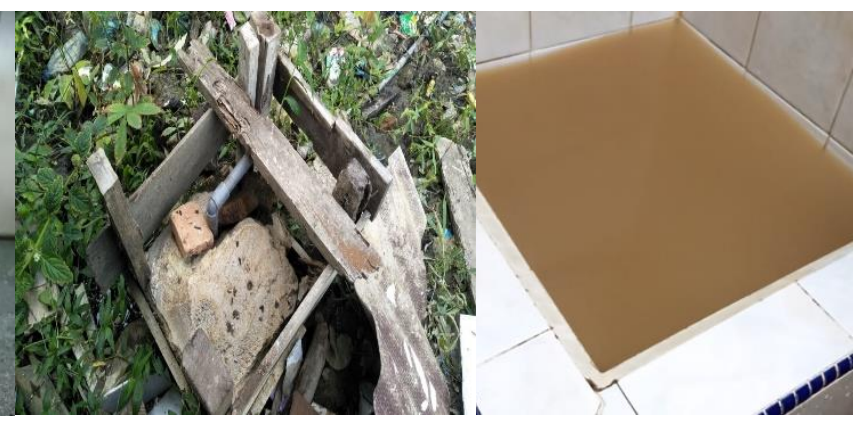

(b) (c)

Gambar 1. Kondisi sumber air desa yaitu air gambut, air sumur bor (asin), dan air sungai Barumun (keruh)

Pada Tahun 2019 Tim Pengabdian USU melalui program KKN PPM USU berada di Desa Sei Siarti dan menemukan salah satu permasalahan yang ada di desa ini adalah sulitnya mengakses ketersediaan air bersih layak konsumsi. Pada saat itu untuk mandi mahasiswa menggunakan air yang ditampung oleh bak penampungan hujan dengan jumlah yang sangat terbatas dan hanya dimiliki oleh sebagian kecil masyarakat. Untuk kebutuhan konsumsi, sebagian besar masyarakat menggunakan air minum isi ulang yang harganya berkisar dua sampai tiga kali lipat dibanding harga air minum isi ulang. Hal ini sangat memberatkan bagi masyarakat dan khususnya mahasiswa KKN pada saat itu. Oleh karena itu maka dibuatlah rekomendasi pelaksanaan pengabdian untuk tahun 2020 dengan tema alat penjernihan air walaupun jarak antara perguruan tinggi dengan Desa lebih dari $200 \mathrm{~km}$ (lebih tepatnya $383 \mathrm{~km}$ ).

Potensi pengolahan air bersih di Desa Sei Siarti ada 2 yaitu air sungai Barumun atau air gambut yang berada di sekeliling Desa dengan mengesampingkan air sumur bor yang rasanya asin karena desa ini sudah berdekatan dengan muara sungai (selat malaka). Dari hasil pengamatan, kondisi air gambut yang berada di desa Sei Siarti juga kurang baik seperti pada umumnya air gambut. Hal ini dapat dilihat secara kasat mata dari warna yang mencolok yaitu berwarna kuning kecoklatan. Selain itu air nya juga memiliki rasa yang payau apabila diminum. Hal ini dapat dilihat dari gambar 1. Warna dari air yang tidak jernih tidak layak untuk diminum dan juga untuk dipakai sebagai dalam kehidupan sehari-hari. Berdasarkan standar baku mutu Permenkes RI No.32/Menkes/2017 air gambut tidak memiliki standar sebagai air bersih karena :

1. Air gambut memiliki warna yang kecoklatan.

2. Air gambut memiliki tingkat keasaman yang tinggi yaitu $\mathrm{Ph} 3,7-5,3$.

3. Zat organik yang terkandung dalam air gambut cukup tinggi sehingga menimbulkan bau.

Meskipun tidak memenuhi standar baku mutu, akan tetapi dikarenakan kuranganya air yang layak digunakan maka mau tidak mau sebagian besar masyarakat sekitar tetap memanfaatkan air gambut ini untuk keperluan sehari-hari. Umumnya mereka akan memompa air ketika terjadi pasang sehingga debit air menjadi tinggi sehingga dapat dipompa menuju rumah. Sebagian besar air digunakan untuk mencuci ataupun mandi. Sebagian lain menggunakannya sebagai air minum. Bagi sebagian masyarakat yang mampu, mereka membeli air minum isi ulang yang harganya cukup mahal karena didatangkan dari daerah yang jauh sehingga harus melalui transportasi darat dan sungai agar bisa sampai di desa. Hal ini semakin membebani masyarakat yang mayoritas adalah bekerja sebagai petani.

Selain air gambut, Desa Sei Siarti dilintasi oleh sebuah sungai besar yaitu Sungai Barumun yang membelah Desa menjadi 2. Pada saat pasang hidup (bahasa orang sekitar) dimana arus dari 
sungai lebih kuat dari arus dari air gambut maka masyarakat memanfaatkannya dengan menyedot langsung air sungai tersebut kedalam bak penampungan yang masyarakat punya dengan kondisi air sungai yang agak keruh terutama saat musim hujan. Namun hal ini akan menjadi kendala jika terjadi pasang mati dimana air sungai tak mampu melawan dari arus air gambut yang ada didarat. Begitu juga jika kondisi sungai sedang banjir sehingga lumpur menyebabkan tingkat kekeruhan air menjadi sangat tinggi. Dengan uraian tadi maka peluang untuk memanfaat potensi sumber air yang ada di desa adalah air sungai barumun.

Metode penjernihan air yang telah dilakukan sebelumnya oleh (Purwoto et al., 2015), ditemukan bahwa alat penjernih air yang paling efektif dalam menjernihkan air sungai adalah melalui proses koagulasi (pengendapan), filtrasi (penyaringan), absorbi (penyerapan), dan adsorpsi (pertukaran ion) yang dilakukan secara bertahap, oleh karena itu tim pengusul akan memasang alat ini pada salah satu fasilitas umum yang digunakan oleh masyarakat yaitu /kantor desa agas masyarakat dapat memanfaatkanya. Alat penjernih air ini dibuat dengan menggunakan tabungtabung yang diisi oleh pasir silika, Manganese Green Sand, Karbon aktif, dan Pasir Zeolit sehingga air yang dihasilkan menjadi jernih dan layak dikonsumsi serta dapat dimanfaatkan oleh masyarakat sekitar. Air sungai yang keruh jika dilakukan pengolahan (treatment) menggunakan koagulan dilanjutkan dengan filtrasi oleh pasir silika, absorben MGS dan karbon aktif, dan diakhiri dengan adsorpsi oleh pasir zeolit dapat menghasilkan air yang jernih. Karbon aktif adalah bahan yang umum digunakan untuk pemurnian dan pemisahan kontaminan dari cairan atau uap. Proses aktifasi dimulai dengan pemilihan material. Bahan baku yang kerap dipergunakan dalam pembuatan karbon aktif adalah kayu, gambut, batu bara, batok kelapa dan residu minyak bumi. Selama ini karbon aktif banyak dipergunakan untuk menyerap bahan-bahan organik. Karbon aktif menghilangkan substansi dari air dengan cara adsorpsi. Karbon aktif menggunakan proses penyerapan fisik di mana gaya Van der Waals menarik bahan organik dari larutan ke permukaan karbon aktif dan dihilangkan dari larutan. Zeolit adalah senyawa zat kimia alumino silikat berhidrat dengan kation natrium, kalium, dan barium. Secara umum, zeolit memiliki molekular struktur yang unik, di mana atom silikon dikelilingi 4 atom oksigen sehingga membentuk semacam jaringan dengan pola yang teratur. Zeolit pada umumnya dapat dibedakan menjadi dua, yaitu zeolit alam dan zeolit sintetik. Zeolit alam biasanya mengandung kation-kation $\mathrm{K}+, \mathrm{Na}+, \mathrm{Ca} 2+$, atau $\mathrm{Mg} 2+$, sedangkan zeolit sintetik biasanya hanya mengandung kation-kation $\mathrm{K}+$ atau $\mathrm{Na}+$ (Heriyani \& Mugisidi, 2016).

\section{METODE PELAKSANAAN}

\subsection{Waktu dan Lokasi}

Penelitian dilakukan di kantor kepala desa Sei Siarti Kecamatan Panai Tengah Kabupaten Labuhanbatu. Penelitian dilaksanakan pada bulan Mei sampai Juli 2020.

\subsection{Bahan dan Alat}

Alat dan bahan yang dibutuhkan dalam proses penjernihan air adalah sebagai berikut:

\subsubsection{Alat}

1. Tabung Filter

2. Pipa

3. Sambungan elbow

2.2.2 Bahan

4. Pompa air
1. PAC
2. Pasir Silika
3. Manganese Green Sand (MGS)
4. Karbon Aktif
5. Pasir Zeolit 


\subsection{Prosedur Kerja}

\subsubsection{Persiapan Alat}

Pada saat air sungai ditampung dalam bak penampungan maka air sungai ditaburi oleh bubuk PAC sehingga kotoran-kotoran yang terlarut dalam air bisa terpisah dan jatuh didasar bak. Selanjutnya air dipompa menuju tabung filter. Tabung pertama diisi dengan pasir silica dan pasir MGS yang berfungsi sebagai filter kotoran yang masuk. Tabung kedua diisi dengan karbon aktif sebagai absorben dan pasir zeolite sebagai adsorpen. Proses penjernihan air sungai melalui 4 tahap yaitu, koagulasi oleh PAC, filtrasi oleh pasir silika dan Manganese Green Sand, absorpsi oleh karbon aktif, dan adsorpsi oleh pasir zeolite untuk menghasilkan air yang jernih (Susilawati, Nasution, \& MN, 2018). Gambar 2 menunjukkan diagram blok dari alat penjernih air.

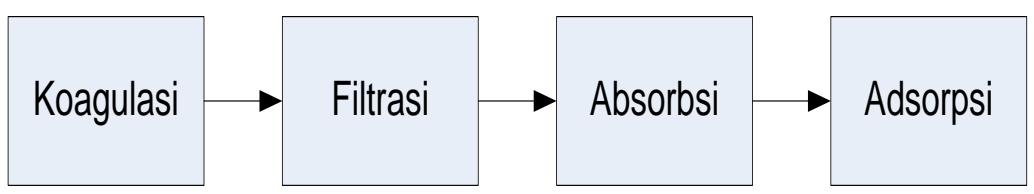

Gambar 2. Skema Penjernihan Air

Setelah proses adsorpsi air kemudian melalui 3 tabung housing filter yang berisi filter spon untuk menyaring air dalam keadaan air sebelum digunakan. Sebelum proses ini dilakukan hal penting lainnya adalah mencuci material filter yang ada di tabung dengan tombol backwash sehingga menghasilkan air yang jernih. Proses pencucian material berkisar antara 2 sampai 3 jam.

\section{HASIL DAN PEMBAHASAN}

Produk yang dihasilkan adalah alat penjernih air sungai menggunakan filter pasir MGS, silika, zeolit, dan karbon aktif yang dimasukkan ke dalam tabung dan dipasang head serta telah dimanfaatkan oleh masyarakat sekitar. Alat penjernihan ini ditunjukkan pada Gambar 3.
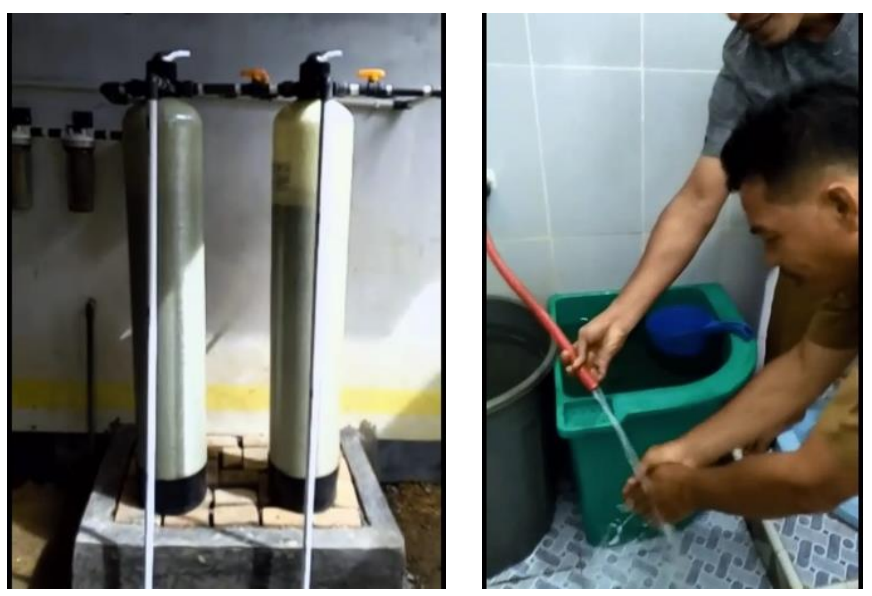

Gambar 3. Alat penjernih air sungai yang telah dimanfaatkan oleh warga desa

Alat ini sudah terpasang dan bekerja dengan menggunakan sumber air sungai barumun yang ditampung dalam bak besar yang berada di belakang kantor desa Sei Siarti yang dapat ditunjukkan oleh gambar 3 . 


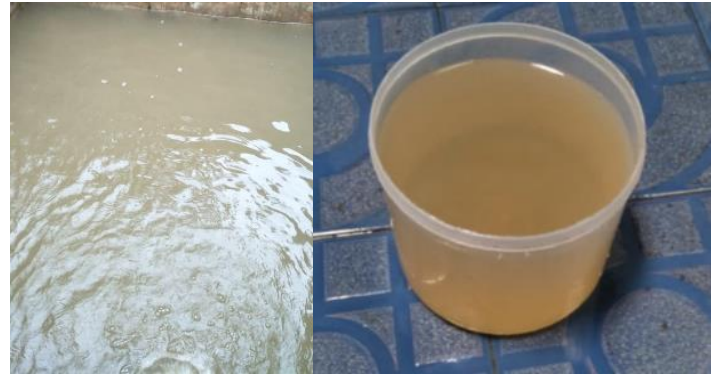

(a)

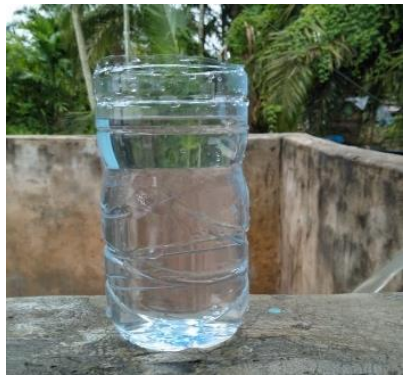

(b)

Gambar 4. Kondisi air yang berada di bak penampungan (a) dan kondisi air hasil penjernihan (b)

Setelah berada di dalam bak penampungan, air tersebut kemudian ditaburkan bubuk PAC untuk mempercepat proses koagulasi (pengendapan) kotoran sungai sehingga kotoran yang memiliki massa jenis lebih besar jatuh ke dasar bak. Kelebihan PAC dibandingkan dengan kaporit adalah PAC tidak memiliki bau dan kapasitas yang besar dimana $5 \mathrm{~g}$ PAC dapat menjernihkan sekitar $1 \mathrm{~m}^{3}$ air. Hal ini berfungsi agar kinerja filter menjadi lebih ringan dan juga memperlambat proses maintenance karena menumpuknya kotoran yang berada di dalam media tabung filter. Setelah dirasa cukup jernih maka air dialirkan menggunakan bantuan mesin air menuju filter dan disaring dengan menggunakan filter pasir MGS dan silika untuk menyaring kotoran-kotoran kecil yang masih terbawa bersama air sungai. Setelah mengalami proses filtrasi, air kemudian melalui proses absorpsi dan adsorpsi dan masuk ke tabung kedua menggunakan filter karbon aktif untuk menyerap bau, warna dan rasa dari air sehingga air layak untuk digunakan dalam keperluan mandi ataupun mencuci. Setelah melalui proses adsorpsi dan absorpsi air keluar melalui housing filter yang berisi filter spons yang dapat dilihat apakah air tersebut sudah jernih sepenuhnya atau belum. Jika belum jernih maka bisa dilakukan proses backwash untuk mencuci media filter yang berada di dalam tabung sehingga media filter menjadi bersih kembali. Hasil dari penjernihan dapat dilihat pada gambar 4 (b) berupa air yang tidak memiliki bau, rasa, dan warna yang jernih sehingga layak untuk dimanfaatkan oleh masyarakat desa.

\section{KESIMPULAN}

\subsection{Kesimpulan}

1. Alat penjernih air dengan prinsip koagulasi, filtrasi, absorpsi, dan adsorpsi telah berhasil dirancang dan diharapkan dapat dengan efektif menjernihkan air sungai Barumun di desa Sei Siarti.

2. Alat penjernih ini memiliki eunggulan dalam proses perawatan yakni tidak perlu secara manual mengeluarkan material filter, akan tetapi hanya menerapkan backwash otomatis untuk membersihkan material filter.

\subsection{Saran}

Untuk pengabdian berikutnya, perlu dikaji juga mengenai metode untuk menjernihkan air gambut yang ada di sungai kecil disepanjang desa. Selain itu, dikarenakan medan tempuh yang sulit terkait dengan jalan menuju lokasi, perlu juga dilakukan pengabdian untuk perbaikan akses jalan menuju ke daerah lokasi pengabdian. 
Azhari, River Water Purifier as an Alternative for Clean Water Supply in Sei Siarti Village, Panai Tengah

District, Labuhanbatu Regency

\section{UCAPAN TERIMAKASIH}

Terima Kasih disampaikan kepada Lembaga Pengabdian Kepada Masyarakat atas dukungan biaya dan Perangkat Desa Sei Siarti Kecamatan Panai Tengah Kabupaten Labuhanbatu atas dukungan pelaksanaan di lapangan

\section{DAFTAR PUSTAKA (REFERENCES)}

Heriyani, O., \& Mugisidi, D. (2016). Pengaruh Karbon Aktif dan Zeolit pada pH Hasil Filtrasi Air Banjir. Seminar Nasional TEKNOKA_FT UHAMKA, 199-202. Retrieved from https://journal.uhamka.ac.id/index.php/teknoka/article/view/893

Purwoto, S., Purwanto, T., Studi, P., Lingkungan, T., Studi, P., Akuntansi, E., ... Kepelatihan, P. (2015). Penjernihan Air Sungai Dengan Perlakuan Koagulasi, Filtrasi, Absorbsi, Dan Pertukaran Ion Setyo Purwoto. Jurnal Teknik Waktu, 13(02), 45-53.

Susilawati, Nasution, T. I., \& MN, N. (2018). Alat Penjernih Air Yang Diintegrasikan Dengan Pompa Air Tenaga Surya. Jurnal Pengabdian Masyarakat USU, 3(2), 312-317.

permenkes-no-32-tahun-2017

[https://peraturan.bpk.go.id/Home/Details/112092/permenkes-no-32-tahun-2017] 